INTERVENTIONAL CARDIOLOGY AND SURGERY

\title{
Long term outcome up to 30 years after the Mustard or Senning operation: a nationwide multicentre study in Belgium
}

\author{
P Moons, M Gewillig, T Sluysmans, H Verhaaren, P Viart, M Massin, B Suys, W Budts, A Pasquet, \\ D De Wolf, A Vliers
}

Heart 2004;90:307-313. doi: 10.1136/hrt.2002.007138

See end of article for authors' affiliations ......................

Correspondence to: Dr Philip Moons, Centre for Health Services and Nursing Research, Katholieke Universiteit Leuven, Kapucijnenvoer 35/4, B-3000 Leuven, Belgium; Philip.Moons@ med.kuleuven.ac.be

Accepted 2 July 2003

\begin{abstract}
Objective: To assess long term outcome of patients who underwent Mustard or Senning repair for transposition of the great arteries up to 30 years earlier.

Design: Retrospective review of medical records.

Setting: The six university hospitals in Belgium with paediatric cardiology departments.

Patients: 339 patients were reviewed, of whom 124 underwent the Mustard procedure and 215 the Senning procedure. This represents almost the entire population of patients in Belgium with either simple or complex transposition.

Main outcome measures: Mortality, morbidity, functional abilities, social integration.

Results: Overall mortality was $24.2 \%$. Early mortality ( $\leqslant 30$ days after surgery) accounted for $16.5 \%$, late mortality for $7.7 \%$. Actuarial survival of early survivors at 10,20 , and 30 years after surgery was $91.7 \%$, $88.6 \%$, and $79.3 \%$, respectively. Patients in the Senning cohort had a slightly better survival rate than those in the Mustard cohort (NS). Baffle obstruction occurred more often after Mustard repair (15.3\%) than after the Senning procedure (1.4\%). Arrhythmia-free survival did not differ between the two cohorts, but was determined by the complexity of the transposition. Survivors of the Senning cohort had better functional status, and tended to engage in more sports activities.

Conclusions: The long term outcome for patients surviving the Mustard or Senning operation was favourable in terms of late mortality, morbidity, functional, and social status. Overall mortality in the Senning cohort did not differ from the Mustard group, but Senning patients had better functional status, greater participation in sports activities, and fewer baffle related problems.
\end{abstract}

$\mathrm{F}$ rom the early 1960s to the mid 1980s, the Mustard and Senning procedures were the treatment of choice for transposition of the great arteries (d-TGA). However, because of complications such as right ventricular failure, arrhythmias, tricuspid valve dysfunction, baffle related problems, and sudden death, ${ }^{1}$ these procedures were replaced by arterial switch operations. Nonetheless, most patients who underwent a Mustard or Senning operation are approaching or have reached adulthood. As a result, cardiologists engaged in the follow up of these patients must deal with multiple residua and sequelae, as well as functional problems associated with these two procedures.

In the last few years there have been several studies reporting long term effects of atrial inflow correction. ${ }^{2-13}$ All but one of these ${ }^{12}$ collected data from single centres, thus overlooking the variability inherent in clinical practice, in particular the different surgical techniques applied in these cases. Moreover, the follow up period in most of these studies was limited to approximately 20 years after atrial repair. Information about the long term follow up, up to 30 years, is sparse. ${ }^{4}$

In the present nationwide multicentre study we therefore undertook a comprehensive evaluation of the long term outcome of patients who underwent Mustard or Senning operations, and compared the outcomes of the two procedures. Long term results were assessed in terms of mortality, morbidity, functional abilities, and social integration.

\section{METHODS}

\section{Study population}

We carried out a retrospective analysis of the medical records of patients who had either simple or complex d-TGA and who had undergone either Mustard or Senning operations. All the patients in this study underwent the operation or received postoperative follow up in one of six paediatric cardiology centres in Belgium. The population of Belgium is approximately 10 million.

The first Mustard procedure in this cohort was done in 1970; the routine use of the technique was abandoned in 1982. In 1977, Senning operations emerged as the treatment of choice in Belgium and were done in some centres until 1993 (fig 1). After 1993, only three patients had the Mustard operation and two the Senning operation. Different surgical techniques were instituted according to the preferences and experience of the local cardiac surgeons. Follow up of the patients was provided by paediatric cardiologists or adult cardiologists with specific training in congenital heart disease, depending on their availability in the respective centres.

In all, 339 patients were included in the study. Demographic and clinical characteristics of the patients are summarised in table 1 . The male to female ratio was 2 to 1 . Simple d-TGA, without concomitant anomalies or with only minor heart defects (for example, atrial septal defect, ventricular septal defect not requiring surgical closure, persisting arterial duct, or left ventricle outflow tract obstruction) was present in 244 patients. Transposition in the remaining 95 patients was associated with other cardiac lesions, such as large ventricular septal defects, pulmonary valve stenosis, coarctation of the aorta, or other less frequent abnormalities.

Blalock-Hanlon septectomy was done in 69 patients. Of these, 28 (40.6\%) underwent the Rashkind procedure before 


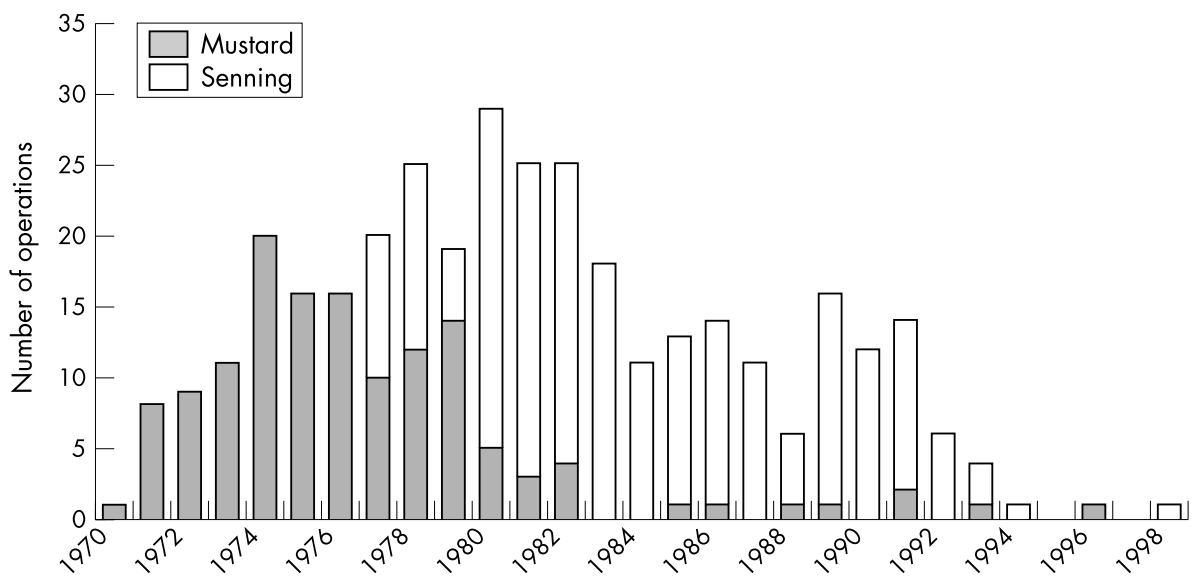

Figure 1 Cumulative numbers of Mustard and Senning operations undertaken each year between 1970 and 1998.

septectomy. Rashkind septostomy was done in 233 patients. Three patients from the Mustard cohort were converted to Senning at 4.3, 4.6, and 11.6 years after the initial Mustard operation, respectively. For further analysis, these patients were placed in the Mustard cohort. Two patients $(0.6 \%)$ were referred for arterial switch conversion at 2.1 and 4.8 years after the Senning operation. Two patients $(0.6 \%)$ underwent heart transplantation at 17.4 and 20.5 years after the Mustard procedure. Fourteen Mustard patients needed a first redo and two needed a second redo, because of venous pathway obstruction $(\mathrm{n}=9)$, pulmonary vein obstruction $(\mathrm{n}=6)$, or baffle leak $(n=1)$. Three Senning patients required a Senning redo operation because of baffle leakage.

\section{Measurement and definitions}

The patients' history and case notes were reviewed to obtain information on concomitant anomalies, interventions, and operations before and after the atrial switch procedure, postoperative complications, survival after repair, occurrence of arrhythmias during the postoperative course, functional status of the patients, and the dates of diagnoses or interventions. This information was based on follow up reports, ECG, ambulatory ECG (24 hour), echocardiogram reports, and catheterisation data. All diagnostic categories, interventions, complications, and arrhythmias were recorded using the short list of EPC codes of the Association for European Paediatric Cardiology (AEPC). ${ }^{14}$ Implementation of these codes allowed standardisation of data collection across all the participating centres.

The functional status of surviving individuals was assessed during the most recent examination. Variables defining functional status included educational level, employment status, level and type of sports activity performed, New York Heart Association (NYHA) functional class, ${ }^{15}$ and ability index. ${ }^{16}$ The ability index was deduced from descriptions assessing physical and social function of each patient. Sports activities were categorised into three levels of intensity ${ }^{17}$ : mild, moderate, and high. Examples of mild intensity sports are billiards, bowling, and golf; moderate intensity sports include badminton, cycling, gymnastics, and dancing; and high intensity sports include basketball and football. ${ }^{17}$

Arrhythmia-free survival was determined in patients surviving the early postoperative period. It was defined as survival after the Mustard or Senning operation without any episode of rhythm or conduction disturbance. In this analysis the following were considered to be rhythm disturbance events: persistent or temporary loss of sinus rhythm; pacemaker implantation; prescription of antiarrhythmic drugs; heart transplantation; episodes of sustained or non-sustained supraventricular rhythm disturbance (atrial flutter, atrial

Table 1 Demographic and clinical characteristics of 339 patients undergoing a Mustard or Senning operation

\begin{tabular}{|c|c|c|c|c|c|c|}
\hline \multirow[b]{2}{*}{ Characteristic } & \multicolumn{2}{|c|}{ Overall group $(n=339)$} & \multicolumn{2}{|c|}{ Mustard $(n=124)$} & \multicolumn{2}{|c|}{ Senning ( $n=215$ ) } \\
\hline & n $(\%)$ & $\begin{array}{l}\text { Median age } \\
\left(Q_{1}-Q_{3}\right)\end{array}$ & $n(\%)$ & $\begin{array}{l}\text { Median age } \\
\left(Q_{1}-Q_{3}\right)\end{array}$ & $n(\%)$ & $\begin{array}{l}\text { Median age } \\
\left(Q_{1}-Q_{3}\right)\end{array}$ \\
\hline Male & $219(64.6 \%)$ & & $84(67.7 \%)$ & & $135(62.8 \%)$ & \\
\hline Female & $120(35.4 \%)$ & & $40(32.3)$ & & $80(37.2 \%)$ & \\
\hline \multicolumn{7}{|l|}{ Cardiac diagnosis } \\
\hline Simple transposition & $244(72.0 \%)$ & & $89(71.8 \%)$ & & $155(72.1 \%$ & \\
\hline Complex transposition & $95(28.0 \%)$ & & $35(28.2 \%)$ & & $60(27.9 \%)$ & \\
\hline -with VSD & $55(57.9 \%)$ & & $20(57.1 \%)$ & & 35 (58.3\%) & \\
\hline -with congenital PS & $29(30.5 \%)$ & & $10(28.6 \%)$ & & $19(31.7 \%)$ & \\
\hline -with CoA & $15(15.8 \%)$ & & $8(22.9 \%)$ & & $7(11.7 \%)$ & \\
\hline \multicolumn{7}{|l|}{ Cardiac interventions } \\
\hline $\begin{array}{l}\text { Surgical atrial septectomy } \\
\text { (Blalock-Hanlon) }\end{array}$ & $69(20.4 \%)$ & $54 \mathrm{~d}(21.5$ to 120$)$ & $49(39.5 \%)$ & $70 \mathrm{~d}(21$ to 153$)$ & $20(9.3 \%)$ & $51 \mathrm{~d}(22$ to 63.5$)$ \\
\hline Balloon atrial septostomy (Rashkind) & $233(68.7 \%)$ & $2 \mathrm{~d}(1$ to 7$)$ & $64(51.6 \%)$ & $4 \mathrm{~d}(1.75$ to 13.75$)$ & $169(78.6 \%)$ & $2 d(1$ to 6$)$ \\
\hline Balloon atrial septostomy redo & 6 & & & & & \\
\hline Atrial switch operation & & & $124(36.5 \%)$ & 1.7 y $(1.2$ to 3.1$)$ & $215(63.5 \%)$ & 0.3 y $(0.1$ to 0.7$)$ \\
\hline First redo & & & 14 & & 3 & \\
\hline Second redo & & & 2 & & & \\
\hline Conversion from Mustard to Senning & & & 3 & & & \\
\hline
\end{tabular}


fibrillation, sinus node dysfunction, paroxysmal atrial tachycardia, sinus bradycardia); atrioventricular (AV) rhythm disturbances (AV junctional tachycardia, or junctional escape bradycardia); ventricular rhythm disturbances (ventricular tachycardia, ventricular flutter, frequent premature ventricular complexes); conduction disorders (first degree $\mathrm{AV}$ block, second degree AV block, complete AV block, complete right bundle branch block); and late mortality that was firmly or potentially related to arrhythmias.

Systemic right ventricular function was evaluated by visual and qualitative assessment of cross sectional echocardiograms. Systemic ventricular function was graded as either normal or mildly disturbed, moderately depressed, or severely depressed, based on descriptions in the medical records.

Tricuspid valve regurgitation data from the echocardiography reports were also collected at the final examination. A rating of $0 / 4$ or $1 / 4$ corresponded to no or mild regurgitation, $2 / 4$ reflected moderate regurgitation, and $3 / 4$ or $4 / 4$ was regarded as severe regurgitation. The methods used to assess ventricular function and tricuspid valve competence in this retrospective study were limited in terms of objective quantifiable measurements. However, an echocardiogram was done systematically during clinical follow up, in contrast to magnetic resonance imaging or angiographic evaluation.

Mortality data were divided into two categories: early and late. Early mortality was defined as death within 30 days following surgery, and late mortality as death occurring after the first 30 days. Patients surviving 30 days after the repair surgery were referred to as early survivors, while patients who are still alive are late survivors.

\section{Statistical analysis}

Descriptive statistics for nominal data were expressed in absolute numbers and percentages. After checking for normality, mean values and standard deviations were calculated for normally distributed continuous variables, and medians and quartiles were computed for continuous variables with a non-normal distribution. Univariate group comparisons for nominal data were done using the $\chi^{2}$ test, or Fisher's exact test if the assumptions for $\chi^{2}$ were not fulfilled. Non-parametric correlations were calculated using Spearman's $\rho$.

Kaplan-Meier curves were plotted to describe the cumulative probability of survival and the probability for arrhythmia-free survival. The log rank test was used to compare survival curves according to the type of atrial repair and the complexity of the transposition.

As the occurrence of rhythm disturbances, systemic ventricular dysfunction, tricuspid valve regurgitation, and baffle related problems may be time dependent, the elapsed time after operation could account for differences between the Mustard and the Senning cohort. Therefore, if significant differences between the two procedures were found, multiple logistic regression analysis was done, adjusting for the type of operation and the length of the postoperative period. Results were reported as odds ratios (OR) and 95\% confidence intervals (CI). The level of significance was set at $\mathrm{p} \leqslant 0.05$.

\section{RESULTS}

\section{Survival}

Eighty two of the 339 patients $(24.2 \%)$ died during the immediate or late postoperative course. Early mortality was observed in 56 patients (16.5\%); this corresponded to two thirds of all fatal cases $(68.3 \%)$. Late mortality was observed in 26 patients $(7.7 \%)$. Of these patients, 10 died in the first year after the operation, and the remaining 16 either died suddenly $(n=6)$ or died from cardiac failure $(n=3)$, during a redo procedure $(n=2)$, or in one case from cardiac arrest associated with fever and apnoea. In four cases, the

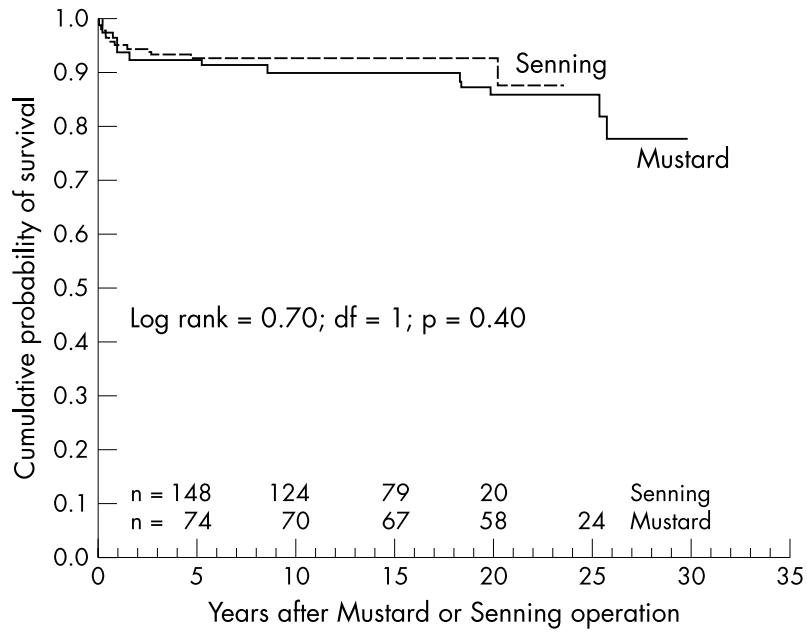

Figure 2 Actuarial survival estimates of 283 patients surviving 30 days after Mustard or Senning operations.

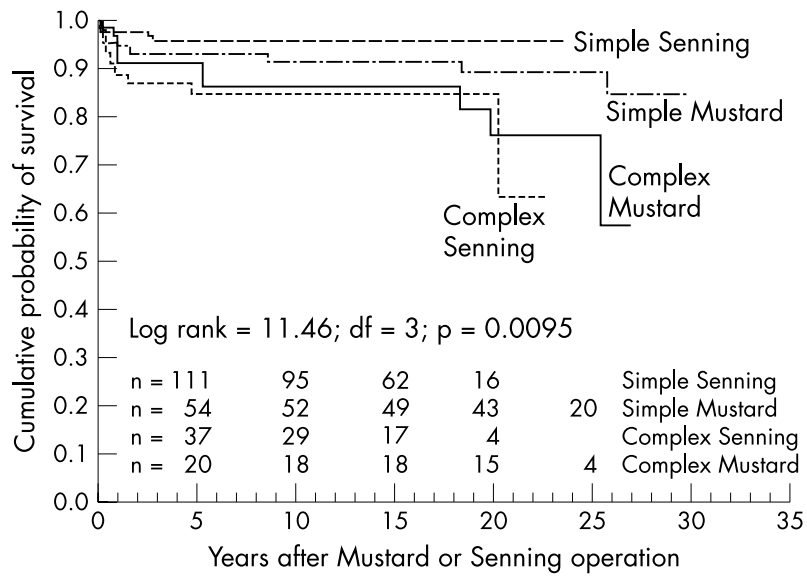

Figure 3 Actuarial survival estimates of 283 patients surviving 30 days after Mustard or Senning operations, with simple or complex transposition of the great arteries.

cause of death was unknown. The actuarial survival at one, five, 10,20 , and 30 years after operation was $80.8 \%, 78.4 \%$, $77.7 \%, 75.1 \%$, and $67.2 \%$, respectively. Excluding early mortality from the survival analysis, the actuarial survival at $10,20,25$, and 30 years after operation was $91.7 \%, 88.6 \%$, $87.5 \%$, and $79.3 \%$, respectively.

High variability in early (range 12.5-23.9\%) and late mortality (range $2.1-15.2 \%$ ) could be observed among the different centres. In the 1970s, operations for congenital heart disease in Belgium were predominantly done at four university hospitals, with a varying case load. From 1975 to 1982 - the period when most Mustard and Senning operations were undertaken-an average of 2.8 procedures per centre were done annually, ranging from 1.0-6.5 operations a year. However, no direct relation was found between the number of operations done and early mortality.

There was a tendency for better overall $(78.6 \% v 71 \%)$ and actuarial survival in patients having the Senning repair compared with the Mustard repair (fig 2). These differences were, however, not significant. In contrast, survival analysis of early survivors according to the type of operation and the complexity of the transposition showed significant differences. Patients having a Senning repair of a simple 
Table 2 Current status of 257 survivors following Mustard or Senning operations

\begin{tabular}{|c|c|c|c|}
\hline & $\begin{array}{l}\text { Overall group } \\
(n=257)\end{array}$ & Mustard $(n=88)$ & Senning $(n=169$ ) \\
\hline Male & $164(63.8 \%)$ & $59(67.0 \%)$ & $105(62.1 \%)$ \\
\hline Female & $93(36.2 \%)$ & $29(33.0 \%)$ & $64(37.9 \%)$ \\
\hline Age (y) (mean (SD)) & $18.2(6.9)$ & $25.1(5.6)$ & $15.1(4.9)$ \\
\hline Range & $1.7-35.4$ & $8.9-35.4$ & $1.7-25.2$ \\
\hline Duration of follow up (y) (mean (SD)) & $17.1(6.0)$ & $22.8(4.9)$ & $14.6(4.6)$ \\
\hline Range & $1.1-29.8$ & $5.2-29.8$ & $1.1-23.6$ \\
\hline $\begin{array}{l}\text { Median duration between last examination } \\
\text { and data collection }\left(Q_{1}-Q_{3}\right)(y)\end{array}$ & $0.8(0.4-1.7)$ & $0.7(0.3-2.2)$ & $0.8(0.4-1.6)$ \\
\hline \multicolumn{4}{|l|}{ Educational level $(\geqslant 18$ years of age) } \\
\hline Vocational high school & $20(23.8 \%)$ & $9(20.9 \%)$ & $11(26.8 \%)$ \\
\hline Technical high school & $8(9.5 \%)$ & $4(9.3 \%)$ & $4(9.8 \%)$ \\
\hline High school & $5(4.8 \%)$ & $3(4.7 \%)$ & $2(4.9 \%)$ \\
\hline Additional vocational high school & $4(4.8 \%)$ & $1(2.3 \%)$ & $3(7.3 \%)$ \\
\hline College & $30(35.8 \%)$ & $16(37.3 \%)$ & $14(34.2 \%)$ \\
\hline University & $7(8.3 \%)$ & $3(7.0 \%)$ & $4(9.8 \%)$ \\
\hline Special education (learning disabilities) & $11(13.1 \%)$ & $8(18.6 \%)$ & $3(7.3 \%)$ \\
\hline \multicolumn{4}{|l|}{ Employment status ( $\geqslant 18$ years of age) } \\
\hline Student & $26(29.2 \%)$ & $4(8.2 \%)$ & $22(55.0 \%)$ \\
\hline Blue collar worker & $21(23.6 \%)$ & $15(30.6 \%)$ & $6(15.0)$ \\
\hline White collar worker & $18(20.2 \%)$ & $12(24.5 \%)$ & $6(15.0)$ \\
\hline Independent & $3(3.4 \%)$ & $3(6.1 \%)$ & $0(0.0 \%)$ \\
\hline Housewife/man & $5(5.6 \%)$ & $3(6.1 \%)$ & $2(5.0 \%)$ \\
\hline Unemployed (looking for work) & $11(12.4 \%)$ & $7(14.3 \%)$ & $4(10.0 \%)$ \\
\hline Unable to work & $5(5.6 \%)$ & $5(10.2 \%)$ & $0(0.0 \%)$ \\
\hline \multicolumn{4}{|l|}{ Functional class } \\
\hline NYHA I & $171(91.9 \%)$ & $50(89.3 \%)$ & $121(93.1 \%)$ \\
\hline NYHA II & $15(8.1 \%)$ & $6(10.7 \%)$ & $9(6.9 \%)$ \\
\hline NYHA III & $0(0.0 \%)$ & $0(0.0 \%)$ & $0(0.0 \%)$ \\
\hline NYHA IV & $0(0.0 \%)$ & $0(0.0 \%)$ & $0(0.0 \%)$ \\
\hline Ability index 1 & $173(86.9 \%)$ & $48(78.7 \%)$ & $125(90.6 \%)$ \\
\hline Ability index 2 & $24(12.1 \%)$ & $13(21.3 \%)$ & $11(8.0 \%)$ \\
\hline Ability index 3 & $2(1.0 \%)$ & $0(0.0 \%)$ & $2(1.4 \%)$ \\
\hline Ability index 4 & $0(0.0 \%)$ & $0(0.0 \%)$ & $0(0.0 \%)$ \\
\hline \multicolumn{4}{|l|}{ Sports activity } \\
\hline Intensive (5-7 days/week) & $3(1.8 \%)$ & $1(1.8 \%)$ & $2(1.9 \%)$ \\
\hline Regularly (1-4 days/week) & $80(49.1 \%)$ & $15(26.8 \%)$ & $65(60.7 \%)$ \\
\hline Occasionally (<once/week) & $28(17.2 \%)$ & $9(16.1 \%)$ & $19(17.8 \%)$ \\
\hline No sports activity & 52 (31.9\%) & $31(55.4 \%)$ & $21(19.6 \%)$ \\
\hline \multicolumn{4}{|l|}{ Level of sports activity } \\
\hline Intensive & $17(16.3 \%)$ & $2(8.3 \%)$ & $15(18.8 \%)$ \\
\hline Moderate & $86(82.7 \%)$ & $21(87.5 \%)$ & 65 (81.3\%) \\
\hline Mild & $1(1.0 \%)$ & $1(4.2 \%)$ & $0(0.0 \%)$ \\
\hline
\end{tabular}

transposition had very good outcome, with a 20 year survival of $95.7 \%$ (fig 3). Patients receiving a Mustard repair of a simple transposition had 10,20, and 30 year survival rates of $91.4 \%, 89.4 \%$, and $84.4 \%$, respectively. Actuarial survival of patients receiving Senning and Mustard operations to repair complex transpositions was comparable, with 10, 20, and 25 year survival rates of $84.4 \%, 84.4 \%$, and $63.3 \%$ for Senning patients, and $86.1 \%, 76.3 \%$, and $76.3 \%$ for Mustard patients. Figure 3 shows that the first year after operation is critical in patients with complex transpositions. Mortality in these patients is $9 \%$.

\section{Current status of survivors}

The mean age of the 257 late survivors was 18.2 years (table 2). They were followed for an average of 17.1 years after the Senning or Mustard procedure. The time period between the final examination and the termination of data collection in the respective centres was 0.8 years, indicating that the data accurately reflect the current status of the survivors.

Educational level attained and employment status were investigated in 106 adult survivors (age $\geqslant 18$ years). About $45 \%$ of these patients had received either a college or a university degree or were pursuing a degree. The distribution of the respective levels of education attained was comparable among the Mustard and Senning cohorts. Special education, however, was more prevalent in the Mustard cohort. The relatively young mean age of the Senning cohort implied that most of these patients were still students, in contrast to the Mustard cohort, in which the majority of the individuals were employed.

In 186 patients, the NYHA class assessed during the final examination was noted in the medical record. Overall, 171 patients were assigned to class I, and 15 were assigned to class II, indicating good functional status. In 199 patients, the ability index was deduced using descriptions assessing the physical and social functioning abilities of each patient. In all, 173 patients were leading a normal life (class 1). Twenty four patients were able to work but experienced intermittent symptoms and some interference with life (class 2 ). Only two patients were unable to work and were limited in all activities (class 3), for extracardiac reasons. The Mustard cohort had significantly fewer class 1 patients and more class 2 patients than the Senning cohort (Fisher's exact test: 6.993; $\mathrm{p}=0.023)$.

The frequency and type of sports activity was reported for 163 patients. About half of these patients engaged in sports on a regular basis. However, the majority of the Mustard 


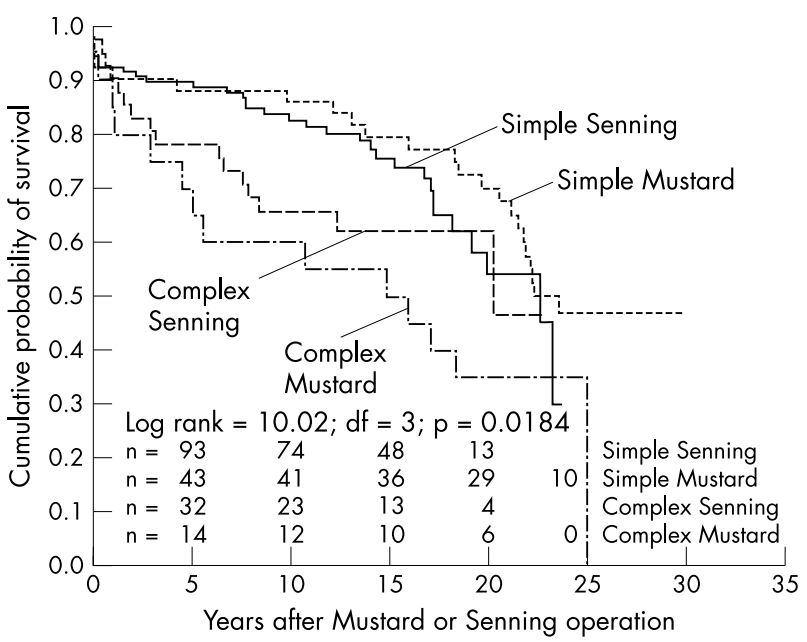

Figure 4 Actuarial arrhythmia-free survival in 283 patients surviving for 30 days after Mustard or Senning operations with simple or complex transposition of the great arteries.

cohort admitted to engaging in no sporting activity. This differed significantly from the Senning cohort $\left(\chi^{2}=23.4\right.$; $\mathrm{df}=3 ; \mathrm{p}<0.001)$. Individuals engaged in sports mostly participated in activities of moderate intensity level.

\section{Arrhythmia-free survival}

Actuarial arrhythmia-free survival 10, 15, 20, and 25 years after surgery was $77.7 \%, 71.1 \%, 57.6 \%$, and $35.7 \%$, respectively. No significant difference in arrhythmia-free survival was observed between the Mustard and Senning operations $(\log$ rank $=0.09 ; \mathrm{df}=1 ; \mathrm{p}=0.76)$. However, according to the complexity of the transposition, significant differences were found (fig 4). Patients receiving Mustard repair of a simple transposition had an arrhythmia-free survival of $86.2 \%$ at 10 years, and $70.1 \%$ at 20 years after surgery. Senning patient with simple transposition had survival rates of $82.6 \%$ and $54.1 \%$ at 10 and 20 years after operation, respectively. Arrhythmia-free survival in patients with complex transposition 10 and 20 years after repair was $60 \%$ and $35 \%$ in Mustard patients, and $64.1 \%$ and $45.4 \%$ in Senning patients. Although patients with simple transposition were free of arrhythmias for a longer period, there was a pronounced decline 15 years after the atrial switch operation.

Of the 257 late survivors, $21(8.2 \%)$ had a documented episode of atrial flutter. Atrial flutter was significantly more prevalent in the Mustard cohort $(20.5 \%)$ than in the Senning cohort $(1.8 \%)\left(\chi^{2}=26.9 ; \mathrm{df}=1 ; \mathrm{p}<0.001\right)$. However, logistic regression showed that atrial flutter was time dependent (OR 1.18, 95\% CI 1.05 to 1.33). Pacemaker implantation was reported in 14 patients (5.5\%). Indications for pacemaker implantation were sick sinus syndrome $(n=7)$, ablation of the Hiss bundle $(n=1)$, complete AV block $(\mathrm{n}=1)$, and unspecified conduction disturbance $(n=2)$. For three patients the reason was not documented in the medical records. Antiarrhythmic drugs were prescribed in 11 patients $(4.3 \%)$.

\section{Systemic ventricular function}

Systemic ventricular function was documented in the medical records of 199 patients. Normal function or mild dysfunction was observed in 176 patients $(88.4 \%)$; moderate or severe dysfunction occurred in $19(9.5 \%)$ and four $(2.0 \%)$, respectively. The Mustard cohort showed moderate (11.7\%) or severe dysfunction (3.3\%) more often than the Senning cohort $(8.6 \%$ and $1.7 \%)$. This difference was, however, not significant. Ventricular dysfunction was not influenced by elapsed time after operation (OR 1.05, 95\% CI 0.95 to 1.17).

\section{Tricuspid valve regurgitation}

Of the 204 patients with reported data on tricuspid valve function, $133(65.2 \%)$ had no or only mild tricuspid regurgitation. Moderate regurgitation was observed in 56 patients $(27.5 \%)$, while severe regurgitation occurred in 15 (7.4\%). Tricuspid valve replacement was done in four patients, and annuloplasty in one.

Severe regurgitation was more prevalent in the Senning cohort (9.2\%) than in the Mustard cohort (3.2\%); this difference was not significant. Tricuspid valve regurgitation was positively correlated with systemic ventricular function $(\rho=0.25 ; p<0.001)$.

\section{Baffle related problems}

The presence or absence of baffle obstruction was documented in the medical records of 197 patients. Nine patients in the Mustard cohort (15.3\%) experienced baffle obstruction, necessitating reintervention. In the Senning cohort, only two patients $(1.4 \%)$ had baffle obstruction. This difference was significant $\left(\chi^{2}=14.9 ; \mathrm{df}=1 ; \mathrm{p}<0.001\right)$. Adjusting for the elapsed time after the operation, the Mustard operation remained significantly associated with baffle related problems (OR 10.03, 95\% CI 1.80 to 55.95).

\section{DISCUSSION}

This is the first multicentre study describing mortality, morbidity, functional status, and aspects of social integration up to 30 years after atrial switch repair for d-TGA. Multicentre follow up studies are often characterised by high attrition because patients are followed by local cardiologists. In this study, the number of patients lost during follow up is very small, because Belgium is a small country with a high population density, easy access to tertiary care, and limited migration of the population. As almost the entire country is covered by the catchment area of the six tertiary care centres, it is assumed that this study covered nearly the entire Belgian population of patients who underwent the Mustard or Senning operation.

\section{Mortality}

In comparison with other published reports, crude mortality rates in this study were relatively high. ${ }^{39} 9^{11}$ There are two possible explanations for this. The first is publication bias. This study confirmed a high variability in mortality rates among centres, depending on the skills of individual surgeons and the experience of the team caring for the patient in the immediate postoperative period. Single centres with a poor clinical outcome are more reluctant to publish their outcome results than centres that perform well. Second, the relatively low exposure of cardiac surgeons and other health care professionals to these specific operations might have led to a slower learning curve. Although some centres undertook only a few Mustard or Senning operations a year, no direct relation was found with outcome.

Although early mortality was relatively high, late mortality was low and actuarial survival of early survivors was higher than in previous studies, ${ }^{3-5} 7^{10}$ both for the overall group and for the Mustard and Senning cohorts separately. Indeed, almost $80 \%$ of the early survivors can continue to survive for up to 30 years after the atrial switch operation.

Mortality data from studies comparing the Mustard and Senning operation are contradictory. ${ }^{2510} 12$ Some studies suggest that survival of patients receiving the Senning operation is better than those receiving the Mustard operation $^{28}{ }^{10}$-not necessarily because of the operative technique but because patients in the Mustard cohort were 
operated on at the beginning of the learning curve and without cold cardioplegia for myocardial protection. ${ }^{6}$ Conversely, data from the only multi-institutional study suggested that short term and intermediate mortality in the Senning cohort was better than in the Mustard cohort mainly in patients with complex transposition. ${ }^{12}$ In line with the findings of Helbing and colleagues, ${ }^{5}$ we found that the Senning operation resulted in slightly better survival rates than the Mustard operation, though the difference was not significant. This was true for both crude mortality and actuarial survival rates.

\section{Morbidity}

Sustained and non-sustained arrhythmias are common after both the Mustard and the Senning operation. This study showed that almost half the patients experience rhythm or conduction disturbances or required antiarrhythmic treatment during their postoperative course in both groups. Patients with complex transposition had a gradual decrease in arrhythmia-free survival. Conversely, patients with simple transposition seem to be less prone to arrhythmias during the first 15 years after atrial inflow correction. After that time, however, a dramatic decline in arrhythmia-free survival was observed, indicating that arrhythmia occurrence several years after the initial operation is an ongoing process. ${ }^{4}$ Direct operative trauma to the sinus node or damage to its blood supply have been suggested as the principal causes of rhythm disturbances in both types of operation..$^{4-6}$

Atrial flutter is an important complication following atrial inflow correction. Ventricular surgery and the use of Dacron baffles, or the presence of residual shunts in patients with complex transpositions, might lead to increased vulnerability to atrial flutter. The incidence of atrial flutter in our Mustard cohort was somewhat higher than in previous reports..$^{2-4} 7$ As atrial flutter is time dependent, ${ }^{2}$ this discrepancy probably reflects the longer follow up period in our patients. This could explain the difference in the frequency of atrial flutter between patients who underwent the Mustard operation $(20.5 \%)$ and those who underwent the Senning operation $(1.8 \%)$. Although it has been argued that atrial flutter is a risk factor for late sudden death, ${ }^{2}$ the results from different studies are still contradictory. ${ }^{7}$ Indeed, while the incidence of atrial flutter in the present study was substantially higher in the Mustard cohort, mortality was comparable with the Senning cohort. Note, however, that the risk of atrial flutter causing sudden death depends on the heart rate, the presence of subobstruction of the venous pathways, and systemic ventricular function.

Ambulatory 24 hour ECG was not done systematically in all patients. Although Holter monitoring is of paramount importance in detecting silent atrial arrhythmias, the predictive value with respect to sudden death is still uncertain. ${ }^{18}$ Thus other strategies to identify patients at risk for sudden death are required.

Key to the successful long term outcome of the Mustard and Senning operation is the fate of the right ventricle in the systemic circulation. ${ }^{2}$ Right ventricular function is therefore a major concern in the long term management of this patient population. The incidence of moderate or severe right ventricular dysfunction in our patients was low (11.6\%) when compared with the reported incidence of depressed right ventricular function, which ranges from $8 \%^{8}$ to approximately $45 \% .^{5}$ This wide variation reflects the qualitative character of echocardiographic evaluation, the lack of uniform definitions of right ventricular function, the time after the operation, the operative technique used, and the patient population under study. Indeed, the multicentre and retrospective character of this study implies that the evaluation of the right ventricle by paediatric and congenital cardiologists involved in the follow up of Mustard and Senning patients is probably not done in a standardised and uniform way. This hampers the comparability of our results with other published data.

In addition to the $11.6 \%$ incidence of ventricular dysfunction in late survivors, patients who died from cardiac failure $(\mathrm{n}=4)$, who received a heart transplant $(\mathrm{n}=2)$, and who underwent arterial switch operation $(n=2)$ should also be considered as having ventricular dysfunction. Although the number of patients with systemic right ventricle dysfunction is likely to increase steadily over the coming years, ${ }^{6}$ our study confirmed previous findings that the right ventricle is capable of performing as the systemic pumping chamber for at least three decades.

\section{Physical and social functioning}

Most long term survivors of the Mustard or Senning operation are in good clinical condition. They display satisfactory functional status and social integration, as indicated by educational level attained, employment status, participation in sports activities, NYHA classification, and ability index. This may contribute to the patients' quality of life.

The high prevalence of learning difficulties in the Mustard cohort may reflect neurological deficits resulting from an extended period of hypoxaemia during infancy. Undertaking the Senning operation at an earlier age, along with simultaneous prostaglandin E treatment, may have decreased these neurological deficits, which in turn would have improved learning and academic performance.

With respect to functional status, patients who had the Senning operation were superior to those having the Mustard procedure. More patients in the Mustard group were unable to work, experienced some interference with their life, and had intermittent symptoms. The higher level of participation in sports activities by the Senning cohort could partly be explained by sports at school in this younger group of patients. With respect to the physical functioning, formal exercise testing data would be very valuable in this patient population. Therefore, this retrospective survey should be expanded to include a prospective study assessing exercise performance, as well as a quantitative evaluation of ventricular function and tricuspid valve competence.

\section{Methodological issues}

The retrospective design of our study necessitated a review of the patients' medical records. Because some variables used in the study were not documented in all cases, missing values were inevitable. In addition, variables were not followed up longitudinally, implying that assessment of determinants of mortality or morbidity using multivariate statistics was not feasible.

A major advantage of multicentre studies is that they yield more generalisable results. However, the heterogeneity of the data and the data collection, based on existing medical records, was an important methodological concern. Examples of such heterogeneity were the definitions of arrhythmias used by the various cardiologists, and the assessment of right ventricular function. Sometimes the exact date of an event or treatment was not known, but only the year was available. In these cases, the most conservative estimation was made by using the first day of that year ( 1 January) in the survival analysis.

\section{Conclusions}

In this study we assessed the long term outcome of patients who underwent a Mustard or Senning operation for transposition of the great arteries. Although early mortality in this study was relatively high, long term results were 
favourable in terms of late mortality, morbidity, functional status, and social integration. While the Senning operation was not superior to the Mustard operation in terms of mortality, Senning patients did show a higher educational level, better functional status, more engagement in sports activities, and fewer baffle obstructions. Other differences between patients receiving either Mustard or Senning repair operations could be explained by the longer postoperative course in the Mustard cohort. Arrhythmia-free survival was better in patients with simple transposition than in complex transposition. This study confirmed a high variability of mortality among different centres, indicating the limited generalisability of single centre experiences.

\section{ACKNOWLEDGEMENTS}

This study was supported by the Belgian National Foundation for Research in Paediatric Cardiology.

\section{Authors' affiliations}

P Moons, Centre for Health Services and Nursing Research, Katholieke Universiteit Leuven, Leuven, Belgium

M Gewillig, W Budts, Division of Congenital Cardiology, University Hospitals of Leuven, Leuven, Belgium

T Sluysmans, A Pasquet, Department of Paediatric Cardiology,

Cliniques Universitaires Saint Luc, Brussels, Belgium

H Verhaaren, D De Wolf, Heart Centre, Ghent University Hospital, Ghent, Belgium

P Viart, Department of Paediatric Cardiology, Hôpital Universitaire Des Enfants Reine Fabiola, Brussels, Belgium

M Massin, Division Paediatric Cardiology, University of Liège at CHR Citadelle, Liège, Belgium

B Suys, Department of Paediatric Cardiology, University Hospital of Antwerp, Edegem, Belgium

A Vliers, Belgian National Foundation for Research in Paediatric Cardiology, Halle, Belgium

*Also Division of Congenital Cardiology, University Hospitals of Leuven, and Belgian National Foundation for Research in Paediatric Cardiology

\section{REFERENCES}

1 Derrick G, Cullen S. Transposition of the great arteries. Curr Treat Options Cardiovasc Med 2000;2:499-506.

2 Sarkar D, Bull C, Yates R, et al. Comparison of long-term outcomes of atrial repair of simple transposition with implications for a late arterial switch strategy. Circulation 1999;100:11176-81.

3 Myridakis DJ, Ehlers KH, Engle MA. Late follow-up after venous switch operation (Mustard procedure) for simple and complex transposition of the great arteries. Am J Cardiol 1994;74:1030-6.

4 Gelatt M, Hamilton RM, McCrindle BW, et al. Arrhythmia and mortality after the Mustard procedure: a 30-year single-center experience. J Am Coll Cardiol 1997;29:194-201.

5 Helbing WA, Hansen B, Ottenkamp J, et al. Long-term results of atrial correction for transposition of the great arteries. Comparison of Mustard and Senning operations. J Thorac Cardiovasc Surg 1994;108:363-72.

6 Gilliam T, Eriksson BO, Solymar L, et al. Status of survivors after atria redirection for transposition of the great arteries: a complete long-term followup. Acta Paediatr 1996;85:832-7.

7 Wilson NJ, Clarkson PM, Barratt-Boyes BG, et al. Long-term outcome after the mustard repair for simple transposition of the great arteries. 28-year followup. J Am Coll Cardiol 1998;32:758-65.

8 Hucin B, Voriskova M, Hruda J, et al. Late complications and quality of life after atrial correction of transposition of the great arteries in 12 to 18 year follow-up. J Cardiovasc Surg 2000;41:233-9.

9 Meijboom F, Szatmari A, Deckers JW, et al. Long-term follow-up (10 to 17 years) after Mustard repair for transposition of the great arteries. J Thorac Cardiovasc Surg 1996;111:1158-68.

10 Birnie D, Tometzki A, Curzio J, et al. Outcomes of transposition of the great arteries in the era of atrial inflow correction. Heart 1998;80:170-3.

11 Reddy V, Sharma S, Cobanoglu A. Atrial switch (Senning procedure) in the era of the arterial switch operation: current indications and results. Eur J Cardiothorac Surg 1996;10:546-50.

12 Wells WJ, Blackstone E. Intermediate outcome after Mustard and Senning procedures: a study by the Congenital Heart Surgeons Society. Semin Thorac Cardiovasc Surg Pediatr Card Surg Annu 2000;3:186-97.

13 Kirjavainen M, Happonen JM, Louhimo I. Late results of Senning operation. J Thorac Cardiovasc Surg 1999; 117:488-95.

14 Association for European Paediatric Cardiology. The European paediatric cardiac code. Cardiol Young 2000;10:1-146.

15 The Criteria Committee of the New York Heart Association. I Diseases of the heart and blood vessels: nomenclature and criteria for diagnosis, 6th ed. Boston: Little Brown, 1964.

16 Somerville J. Congenital heart disease in adults and adolescents. $\mathrm{Br}$ Heart J 1986;56:395-7.

17 Baecke JA, Burema J, Frijters JE. A short questionnaire for the measurement of habitual physical activity in epidemiological studies. Am J Clin Nutr 1982;36:936-42.

18 The Task Force on the management of grown up congenital heart disease of the European Society of Cardiology. Management of grown up congenital heart disease. Eur Heart J 2003;24:1035-84

\section{FROM BMJ JOURNALS}

\section{Dangers of spironolactone in congestive heart failure}

Please visit the Heart website [www.heartinl. com] for a link to the full text of this article.

$\mathrm{S}$ pironolactone reduces morbidity and mortality in patients with severe congestive heart failure and guidelines have recommended adding spironolactone to treatment with ACE inhibitors and $\beta$ blockers. A prospective observational study in Copenhagen has highlighted the danger of renal impairment and of hyperkalaemia.

The study included 125 consecutive patients at an outpatient clinic for congestive heart failure. All patients had a left ventricular ejection fraction (LVEF) of $45 \%$ or less or were taking spironolactone. (Sixty patients were already taking spironolactone on entry to the 2 year study and 65 began spironolactone during the study.) Ninety three patients were receiving a potassium supplement at baseline. Supplementation was stopped in 66 patients and gradually reduced in the other 27. Mean peak serum concentrations of creatinine and potassium were $167.6 \mu \mathrm{mol} / \mathrm{L}$ and $5.0 \mathrm{mmol} / \mathrm{L}$. Serum creatinine increased during the study by $20 \%$ in over a half $(55 \%)$ of patients, by $50 \%$ in a quarter $(24 \%)$ of patients, and by $100 \%$ in a tenth $(9 \%)$. Seventy three patients $(58 \%)$ had a serum creatinine of more than 130 $\mu \mathrm{mol} / \mathrm{L}$ and 28 (18\%) more than $220 \mu \mathrm{mol} / \mathrm{L}$. Serum potassium concentrations of $>5,>5.5$, and $>6 \mathrm{mmol} / \mathrm{L}$ occurred in $45(36 \%), 21(17 \%)$, and $13(10 \%)$. The risk of a $50 \%$ or greater increase in serum creatinine increased by $74 \%$ for every 10 year increase in age and decreased by $6 \%$ for every $10 \%$ increase in LVEF. The risk of severe hyperkalaemia (serum potassium $>6 \mathrm{mmol} / \mathrm{L}$ ) increased 3.4 fold for each increase in New York Heart Association functional class and decreased by $63 \%$ for each $10 \%$ increase in LVEF.

Spironolactone may be associated with more frequent adverse effects than is generally realised. Doses of other diuretics may need to be reduced and frequent laboratory monitoring is essential.

A BMJ 2003; 327:1141-1142. 